\title{
ВЫБОРЫ ГЛАВ РЕГИОНОВ В РОССИИ В 2015 ГОДУ (АНАЛИЗ ПРОЦЕССА ИЗБИРАТЕЛЬНОЙ КАМПАНИИ И ЕЕ РЕЗУЛЬТАТОВ)
}

\author{
E. B. Махора \\ (Московский гуманитарный университет)
}

Аннотация: В статье анализируются процесс и итоги выборов глав регионов России осенью 2015 г., в том числе в Иркутской области. На основе исследования процесса и результатов этой избирательной кампании выявляются некоторые особенности выборов глав регионов после возвращения в электоральный процесс процедуры выборов региональных руководителей.

Ключевые слова: выборы; голосование; губернатор; избиратель; электоральный процесс; избирательная кампания; регионы России

\section{AN INSIGHT INTO THE 2015 GUBERNATORIAL ELECTION CAMPAIGN: EVALUATING THE OUTCOME}

\author{
E. V. Makhora \\ (Moscow University for the Humanities)
}

\begin{abstract}
The article deals with the process and the outcome of regional governors' elections of 2015, with a special focus on the Irkutsk region. We single out some common features of the first gubernatorial election campaigns since Russia has reverted to the previous procedure for electing regional governors.

Keywords: elections; voting; governor; voter; electoral process; election campaign; regions of Russia
\end{abstract}

Цель данной статьи заключается в анализе результатов выборов глав регионов в избирательной кампании 2015 г. и выявлении некоторых ее особенностей.

Осенняя 2015 г. кампания по выборам губернаторов проводилась в 21 субъекте Российской Федерации. Срок полномочий избираемых глав регионов составляет 5 лет. Выборы в указанных субъектах Российской Федерации проводятся по мажоритарной избирательной системе абсолютного большинства. Избранным считается зарегистрированный кандидат, 
который получил более 50\% голосов избирателей, принявших участие в голосовании.

На должность глав регионов в целом было выдвинуто 142 кандидата (141 - от 27 политических партий и 1 - в порядке самовыдвижения). В итоге зарегистрированы 98 кандидатов. По итогам регистрации на выборную должность руководителя высшего исполнительного органа государственной власти 21 субъекта Российской Федерации в среднем претендовали 4-5 зарегистрированных кандидатов (ЦИК ..., 2015: Электр. ресурс).

Зарегистрированные кандидаты представляли 16 партий. Больше всего претендентов было от «Единой России», КПРФ и ЛДПР (по 20 от каждой). От партии «Справедливая Россия» в выборах участвовали 17 кандидатов, от партии «Патриоты России» -5 , от остальных партий - по 1-2 кандидата.

Часть кандидатов были отсеяны. По регионам показатели отсева кандидатов существенно различаются: от нулевого в Республике Татарстан, Костромской, Ростовской областях и Еврейской автономной области до 58\% в Чувашской Республике. Большая часть случаев отсева (26) связана с тем, что кандидат не представил документы на регистрацию. В 13 случаях кандидаты выбыли по личному заявлению. Отказов в регистрации зарегистрировано всего 4. Во всех случаях отказ связан с муниципальным фильтром.

Самый молодой претендент на пост главы региона - кандидат в губернаторы Ростовской области от ЛДПР - И. А. Новиков (31 год). Самый старший - кандидат на пост главы администрации Тамбовской области А. М. Сафонов от фракции «Справедливая Россия» (72 года).

Центризбирком (ЦИК) РФ представил 18.11.2015 г. так называемую «Зеленую книгу» - сведения о нарушениях на выборах 13 сентября 2015 г. и принятых мерах реагирования.

В ходе подготовки и проведения выборов в единый день голосования 13 сентября 2015 г. в Центризбирком поступило и было рассмотрено 1587 обращений, содержащих сведения о нарушениях избирательного законодательства. Факты нарушений подтвердились в 170 обращениях, или 10,7\%.

Член ЦИК от фракции «Справедливая Россия» С. А. Даниленко, представлявший сведения, заявил, что количество подтвержденных нарушений составило более $10 \%$, что показывает уменьшение их числа в сравнении с предыдущим годом (тогда их было более 15\%). Большинство обращений касались неправомерности действий членов местных избирательных комиссий. Таким образом, следует подчеркнуть, что в избирательном процессе, возможно, намечается тенденция уменьшения количества нарушений.

Результаты выборов глав регионов выглядят следующим образом 
(см. таб. 1).

\begin{tabular}{|c|c|c|c|c|c|c|}
\hline$N^{o}$ & Регион & Явка, \% & $\begin{array}{c}\text { Победи- } \\
\text { тель }\end{array}$ & $\begin{array}{c}\text { Резуль- } \\
\text { тат по- } \\
\text { бедителя, } \\
\%\end{array}$ & $\begin{array}{c}\text { Второе } \\
\text { место }\end{array}$ & $\begin{array}{c}\text { Резуль- } \\
\text { тат } \\
\text { второго } \\
\text { места, \% }\end{array}$ \\
\hline 1 & $\begin{array}{c}\text { Кемеров- } \\
\text { ская об- } \\
\text { ласть }\end{array}$ & 92,13 & $\begin{array}{c}\text { Аман Ту- } \\
\text { леев }\end{array}$ & 96,69 & $\begin{array}{c}\text { Алексей } \\
\text { Диденко } \\
\text { (ЛДПР) }\end{array}$ & 1,78 \\
\hline 2 & $\begin{array}{c}\text { Республи- } \\
\text { ка Татар- } \\
\text { стан }\end{array}$ & 84,21 & $\begin{array}{c}\text { Рустам } \\
\text { Минниха- } \\
\text { нов }\end{array}$ & 94,47 & $\begin{array}{c}\text { Хариз } \\
\text { Мирга- } \\
\text { лимов } \\
\text { (КПРФ) } \\
\end{array}$ & 2,56 \\
\hline 3 & $\begin{array}{c}\text { Пензен- } \\
\text { ская об- } \\
\text { ласть }\end{array}$ & 62,66 & $\begin{array}{l}\text { Иван Бе- } \\
\text { лозерцев }\end{array}$ & 86,04 & $\begin{array}{c}\text { Владимир } \\
\text { Симагин } \\
\text { (КПРФ) }\end{array}$ & 7,75 \\
\hline 4 & $\begin{array}{c}\text { Тамбов- } \\
\text { ская об- } \\
\text { ласть }\end{array}$ & 57,77 & $\begin{array}{c}\text { Александр } \\
\text { Никитин }\end{array}$ & 85,47 & $\begin{array}{c}\text { Андрей } \\
\text { Жидков } \\
\text { (КПРФ) }\end{array}$ & 6,89 \\
\hline 5 & $\begin{array}{c}\text { Красно- } \\
\text { дарский } \\
\text { край } \\
\end{array}$ & 46,47 & $\begin{array}{c}\text { Вениамин } \\
\text { Кондра- } \\
\text { тьев } \\
\end{array}$ & 83,68 & $\begin{array}{c}\text { Николай } \\
\text { Осадчий } \\
\text { (КПРФ) }\end{array}$ & 7,84 \\
\hline 6 & $\begin{array}{c}\text { Ленин- } \\
\text { градская } \\
\text { область }\end{array}$ & 44,52 & $\begin{array}{l}\text { Александр } \\
\text { Дрозденко }\end{array}$ & 82,1 & $\begin{array}{c}\text { Николай } \\
\text { Кузьмин } \\
\text { (КПРФ) }\end{array}$ & 6,98 \\
\hline 7 & $\begin{array}{c}\text { Брянская } \\
\text { область }\end{array}$ & 57,43 & $\begin{array}{c}\text { Александр } \\
\text { Богомаз }\end{array}$ & 79,96 & $\begin{array}{c}\text { Михаил } \\
\text { Иваков } \\
\text { («Патрио- } \\
\text { ты Рос- } \\
\text { сии») }\end{array}$ & 9,61 \\
\hline 8 & $\begin{array}{c}\text { Ростов- } \\
\text { ская об- } \\
\text { ласть }\end{array}$ & 48,51 & $\begin{array}{l}\text { Василий } \\
\text { Голубев }\end{array}$ & 78,21 & $\begin{array}{c}\text { Николай } \\
\text { Коло- } \\
\text { мейцев } \\
(\text { КПРФ) }\end{array}$ & 11,66 \\
\hline 9 & $\begin{array}{l}\text { Камчат- } \\
\text { ский край }\end{array}$ & 31,88 & $\begin{array}{c}\text { Владимир } \\
\text { Илюхин }\end{array}$ & 75,48 & $\begin{array}{l}\text { Михаил } \\
\text { Смагин } \\
(\text { КПРФ) }\end{array}$ & 9,66 \\
\hline 10 & $\begin{array}{c}\text { Еврейская } \\
\text { автоном- } \\
\text { ная об- } \\
\text { ласть } \\
\end{array}$ & 31,87 & $\begin{array}{l}\text { Александр } \\
\text { Левинталь }\end{array}$ & 75,42 & $\begin{array}{c}\text { Кон- } \\
\text { стантин } \\
\text { Лазарев } \\
(\text { КПРФ) }\end{array}$ & 14,37 \\
\hline 11 & $\begin{array}{c}\text { Калужская } \\
\text { область }\end{array}$ & 36,28 & $\begin{array}{c}\text { Анатолий } \\
\text { Артамо- } \\
\text { нов }\end{array}$ & 71,67 & $\begin{array}{c}\text { Николай } \\
\text { Якшин } \\
\text { (КПРФ) }\end{array}$ & 12,06 \\
\hline
\end{tabular}




\begin{tabular}{|c|c|c|c|c|c|c|}
\hline 12 & $\begin{array}{c}\text { Калинин- } \\
\text { градская } \\
\text { область }\end{array}$ & 39,59 & $\begin{array}{l}\text { Николай } \\
\text { Цуканов }\end{array}$ & 70,41 & $\begin{array}{c}\text { Игорь } \\
\text { Ревин } \\
\text { (КПРФ) }\end{array}$ & 10,22 \\
\hline 13 & $\begin{array}{c}\text { Сахалин- } \\
\text { ская об- } \\
\text { ласть } \\
\end{array}$ & 37,59 & $\begin{array}{l}\text { Олег Ко- } \\
\text { жемяко }\end{array}$ & 67,8 & $\begin{array}{c}\text { Светлана } \\
\text { Иванова } \\
(\text { КПРФ) } \\
\end{array}$ & 20,27 \\
\hline 14 & $\begin{array}{c}\text { Костром- } \\
\text { ская об- } \\
\text { ласть } \\
\end{array}$ & 36,54 & $\begin{array}{c}\text { Сергей } \\
\text { Ситников }\end{array}$ & 66,77 & $\begin{array}{c}\text { Валерий } \\
\text { Ижицкий } \\
(\text { КПРФ) }\end{array}$ & 20,79 \\
\hline 15 & $\begin{array}{c}\text { Чувашская } \\
\text { Республи- } \\
\text { ка }\end{array}$ & 58,65 & $\begin{array}{c}\text { Михаил } \\
\text { Игнатьев }\end{array}$ & 65,54 & $\begin{array}{c}\text { Олег } \\
\text { Николаев } \\
\text { («Спра- } \\
\text { ведливая } \\
\text { Россия») }\end{array}$ & 14,73 \\
\hline 16 & $\begin{array}{c}\text { Смолен- } \\
\text { ская об- } \\
\text { ласть }\end{array}$ & 28,77 & $\begin{array}{c}\text { Алексей } \\
\text { Остров- } \\
\text { ский } \\
\text { (ЛДПР) }\end{array}$ & 66,18 & $\begin{array}{c}\text { Сергей } \\
\text { Лебедев } \\
\text { («Спра- } \\
\text { ведливая } \\
\text { Россия») }\end{array}$ & 12,42 \\
\hline 17 & $\begin{array}{l}\text { Омская } \\
\text { область }\end{array}$ & 33,78 & $\begin{array}{l}\text { Виктор } \\
\text { Назаров }\end{array}$ & 60,02 & $\begin{array}{c}\text { Олег Де- } \\
\text { нисенко } \\
(\text { КПРФ) }\end{array}$ & 28,15 \\
\hline 18 & $\begin{array}{c}\text { Архан- } \\
\text { гельская } \\
\text { область } \\
\end{array}$ & 20,99 & $\begin{array}{c}\text { Игорь Op- } \\
\text { лов }\end{array}$ & 53,25 & $\begin{array}{c}\text { Ольга } \\
\text { Осицына } \\
\text { (ЛДПР) }\end{array}$ & 19,22 \\
\hline 19 & $\begin{array}{c}\text { Республи- } \\
\text { ка Марий } \\
\text { Эл }\end{array}$ & 47,09 & $\begin{array}{c}\text { Леонид } \\
\text { Маркелов }\end{array}$ & 50,76 & $\begin{array}{c}\text { Сергей } \\
\text { Мамаев } \\
(\text { КПРФ) }\end{array}$ & 32,31 \\
\hline 20 & $\begin{array}{c}\text { Амурская } \\
\text { область }\end{array}$ & 33,53 & $\begin{array}{c}\text { Александр } \\
\text { Козлов }\end{array}$ & 50,64 & $\begin{array}{c}\text { Иван } \\
\text { Абрамов } \\
\text { (ЛДПР) }\end{array}$ & 28,3 \\
\hline 21 & $\begin{array}{c}\text { Иркутская } \\
\text { область }\end{array}$ & 29,19 & $\begin{array}{c}\text { Сергей } \\
\text { Ерощенко }\end{array}$ & 49,60 & $\begin{array}{c}\text { Сергей } \\
\text { Левченко } \\
(\text { КПРФ) }\end{array}$ & 36,61 \\
\hline
\end{tabular}

(Гармоненко и др., 2015: Электр. ресурс).

На основе анализа этих данных можно сделать следующие выводы:

1) Регионы существенно различаются по уровню участия граждан в выборах. Самая высокая явка избирателей была в Кемеровской области - 92,13\%. Самая низкая - 20,99\% в Архангельской области. До 30\% не дотянула явка избирателей в Смоленской и Иркутской областях. Немногим более 30\% оказалась явка в Амурской и Омской областях, Камчатском крае, Еврейской автономной области. Низкая явка на выборах глав регионов обусловлена не только растущей аполитичностью россиян 
в последние годы, но и, вероятно, недовольством населения результатами действующей власти и неверием в возможность повлиять на происходящие процессы в регионе;

2) Судя по результатам победителей в этой избирательной кампании, выборы в большинстве регионов носили, скорее всего, неконкурентный характер. При анализе электоральной конкуренции и критериев ее измерения «наиболее распространенной является предложенная В. Гельманом и Е. Поповой методика количественных оценок, согласно которой если результат «кандидата-инкумбента» на выборах меньше двух третей, тогда можно говорить о том, что конкурентность и состязательность присутствуют...» (Ашихмина, 2007: Электр. ресурс);

3) Исходя из отмеченного выше, прошедшие выборы можно назвать конкурентными в Омской, Архангельской, Амурской и Иркутской областях, а также в Республике Марий Эл в связи с тем, что победители набрали явно менее две трети голосов. Наименьший отрыв победителя от кандидата, занявшего второе место, был в Иркутской области, где кандидату от партии власти С. В. Ерощенко не удалось победить в первом туре, что предопределило необходимость второго тура, в котором он потерпел поражение;

4) Далее следует отметить, что большинство кандидатов, занявших вторые места, а это в 15-ти из 21 региона, оказались от КПРФ, что свидетельствует о значительном потенциале этой партии на предстоящих осенью 2016 г. выборах в Государственную Думу;

5) На посты глав регионов баллотировались 7 женщин и 91 мужчина.

Все кандидаты, победившие на выборах - мужчины, среди кандидатов, занявших второе место лишь 2 женщины. Все это свидетельствует о сильно выраженном «маскулинном» составе региональных руководителей в России. Во многих других странах женщины более активно и успешно участвуют в региональных выборах;

6) Как было отмечено выше, в Иркутской области потребовался второй тур выборов. Это произошло впервые на выборах глав регионов с 2012 г., то есть, после завершения почти десятилетнего периода назначения глав регионов и возвращения губернаторских выборов.

В иркутских выборах 13 сентября 2015 г. участвовали четыре кандидата: помощник депутата Госдумы РФ Л. И. Егорова от фракции «Справедливая Россия», временно исполняющий обязанности губернатора Иркутской области С. В. Ерощенко от партии «Единая Россия», директор ООО «Группа “Континент”», депутат законодательного собрания Иркутской области О. Н. Кузнецов от партии ЛДПР и заместитель председателя комитета Госдумы РФ по энергетике и первый секретарь Иркутского областного отделения КПРФ С. Г. Левченко. Ни один из них в первом туре 
не набрал необходимого для победы числа голосов (более половины голосов избирателей, отданных за всех кандидатов). Во второй тур вышли С.В. Ерощенко $(49,60 \%)$ и С. Г. Левченко (36,61\%), с отрывом друг от друга в $12,99 \%$.

Во втором туре, который состоялся 27 сентября 2015 г., С. Г. Левченко поддержали 56,39\% избирателей, С. В. Ерощенко - 41,46\%. Таким образом, С. Г. Левченко победил с преимуществом в 14,93 \%. По сравнению с первым туром он добавил $19,78 \%$, его соперник утратил $8,14 \%$. Обострившаяся борьба во втором туре привлекла большее внимание избирателей. Явка избирателей во втором туре составила 35,5\%, что на 6,31\% больше, чем в первом туре.

Информации о нарушениях в первом туре голосования от Избирательной комиссии Иркутской области не поступало.

По словам, председателя Избирательной комиссии Иркутской области Э. И. Девицкого, всего 27 сентября 2015 г. на избирательных участках находились 5196 наблюдателей. От «Единой России» было направлено 1311 наблюдателей, от КПРФ - 1093, от С. В. Ерощенко - 1513, от С. Г. Левченко - 1279.

Кроме того, в участковых комиссиях присутствовали члены с правом совещательного голоса - 1723 чел., из которых 1269 были направлены кандидатами, а 454 - политическими партиями.

Ни один наблюдатель не был удален с избирательного участка, но имел место быть случай, когда одного члена комиссии с правом совещательного голоса отстранили от работы в Черемхове из-за агитации в пользу одного из кандидатов во время выездного голосования.

Таким образом, иркутская история показывает, что, несмотря на огромные преимущества, кандидата от «партии власти» можно победить. Это тем более возможно, если губернатор-«единорос» не может добиться позитивных результатов в развитии области. А дела в Иркутской области в последнее время шли на спад. Так, за последние три года «государственный долг региона вырос в три раза», а ведь область в 1990-е годы была донором федерального бюджета (Нехайчук, Терентьева, 2016: Электр. ресурс).

Победа С. Г. Левченко, по словам Председателя ЦК КПРФ Г. А. Зюганова, может быть связана, с тем, что в ходе подготовки ко второму туру Левченко предложил программу вывода области из кризиса, программу развития производства, поддержки социальной сферы. Эксперты назвали Иркутскую область среди регионов с высоким уровнем конкуренции, продемонстрированной в ходе последней выборной кампании. Избирательная кампания в Иркутской области особенно поучительна накануне выборов в Государственную Думу. 


\section{СПИСОК ЛИТЕРАТУРЫ}

Ашихмина, Я.Г. (2007) Конкуренция элит на выборах как критерий современной демократии [Электронный ресурс]//Политэкс. № 2.URL:http:// www.politex.info/content/view/341/30/ (дата обращения: 26.02.2016).

Гармоненко, Д., Разуваев, В., Горбачев, А., Разуваев, В. (2015) Губернаторы ушли в электоральный отрыв [Электронный ресурс] // Независимая газета. 15 сентября. URL: http://www.ng.ru/politics/2015-09-15/1_ gubernatory.html (дата обращения: 26.02.2016).

Нехайчук, Ю., Терентьева, А. (2016) «Я не могу защищать интересы частных инвесторов, для этого есть правоохранительные органы». Как губернатор-коммунист Сергей Левченко управляет Иркутской областью и как ему в этом может помочь знакомство с Сергеем Чемезовым и Юрием Чайкой [Электронный ресурс] // Ведомости. 17 февраля. URL: https:// www.vedomosti.ru/politics/characters/2016/02/17/629982-ya-ne-moguzaschischat-interesi-chastnih-investorov-dlya-etogo-est-pravoohranitelnieorgani/ (дата обращения: 26.02.2016).

ЦИК получил почти 1,6 тыс. сообщений о нарушениях на выборах (2015) [Электронный ресурс] // ТАСС. Информационное агентство России. 18 ноября. URL: http://tass.ru/politika/2449769/ (дата обращения 26.02.2016).

Махора Екатерина Витальевна - аспирант кафедры философии, культурологии и политологии Московского гуманитарного университета. Адрес: 111395, Россия, г. Москва, ул. Юности, д. 5 . Тел.+7 (985) 265-43-97. Эл. адрес: katrinmak17@rambler.ru. Научный руководитель - д-р полит. н., профессор В. И. Буренко.

Makhora Ekaterina Vitalyevna, Postgraduate student, Department of Philosophy, Politology and Culturology, Moscow University for the Humanities. Tel.: +7 (985)265-43-97. E-mail: katrinmak17@rambler.ru. Research advisor Doctor of Political science, Professor V.I. Burenko. 